\title{
Performance-Led Research in the Wild
}

\author{
STEVE BENFORD, CHRIS GREENHALGH, ANDY CRABTREE, MARTIN FLINTHAM, \\ BRENDAN WALKER, JOE MARSHALL, BORIANA KOLEVA, \\ and STEFAN RENNICK EGGLESTONE, The University of Nottingham \\ GABRIELLA GIANNACHI, University of Exeter \\ MATT ADAMS, NICK TANDAVANITJ, and JU ROW FARR, Blast Theory
}

We explore the approach of performance-led research in the wild in which artists drive the creation of novel performances with the support of HCI researchers that are then deployed and studied at public performance in cultural settings such as galleries, festivals and on the city streets. We motivate the approach and then describe how it consists of three distinct activities - practice, studies and theory - that are interleaved in complex ways through nine different relationships. We present a historical account of how the approach has evolved over a fifteen-year period, charting the evolution of a complex web of projects, papers, and relationships between them. We articulate the challenges of pursuing each activity as well as overarching challenges of balancing artistic and research interests, flexible management of relationships, and finally ethics.

Categories and Subject Descriptors: H5.2 [Information Interfaces and Presentation]: User InterfacesUser-centered design; interaction styles; theory and methods

General Terms: Human Factors, Design, Theory

Additional Key Words and Phrases: Art, performance, methodology, ethnography, theory, performance-led, in the wild

\section{ACM Reference Format:}

Beneford, S., Greenhalgh, C., Crabtree, A., Flintham, M., Walker, B., Marshall, J., Koleva, B., Rennick Egglestone, S., Giannachi, G., Adams, M., Tandavanitj, N., and Row Farr, J. 2013. Perforarnnce-led research in the wild. ACM Trans. Comput.-Hum. Interact. 20, 3, Article 14 (July 2013), 22 pages.

DOI : http://dx.doi.org/10.1145/2491500.2491502

\section{INTRODUCTION}

HCI has a growing interest in artistic and cultural applications of computing, working with artists to create and study public experiences in settings such as galleries, theaters, theme parks, and the city streets. We shall argue that projects that combine the staging of public artworks with exploratory HCI research constitute a form of research in the wild in the sense that they engage "real" users with emerging technologies in "real" settings under demanding conditions of actual use. Moreover, these

The authors gratefully acknowledge the support of the Engineering and Physical Sciences Research Council (EPSRC) through the Horizon Digital Economy Hub and Doctoral Training Centre and also the Widespread Adoption of Ubiquitous Computing platform grant (EP/F03038X/1).

Authors' addresses: S. Benford, C. Greenhalgh, A. Crabtree, M. Flintham, B. Walker, J. Marshall, B. Koleva, and S. Rennick Egglestone, School of Computer Science (Mixed Reality Lab), The University of Nottingham, Nottingham NG8 1BB, UK; G. Giannachi, Centre for Intermedia, Department of English, University of Exeter, Prince of Wales Road, Exeter, Devon, UK, EX4 4SB; M. Adams, N. Tandavanitj, and J. Row Farr, Blast Theory, Unit 5, 20 Wellington Road, Portslade Brighton BN41 1DN, UK; email: sdb@cs.nott.ac.uk.

Permission to make digital or hard copies of part or all of this work for personal or classroom use is granted without fee provided that copies are not made or distributed for profit or commercial advantage and that copies show this notice on the first page or initial screen of a display along with the full citation. Copyrights for components of this work owned by others than ACM must be honored. Abstracting with credit is permitted. To copy otherwise, to republish, to post on servers, to redistribute to lists, or to use any component of this work in other works requires prior specific permission and/or a fee. Permissions may be requested from Publications Dept., ACM, Inc., 2 Penn Plaza, Suite 701, New York, NY 10121-0701 USA, fax +1 (212) 869-0481, or permissions@acm.org.

(c) 2013 ACM 1073-0516/2013/07-ART14 $\$ 15.00$

DOI : http://dx.doi.org/10.1145/2491500.2491502 
engagements are often sustained over considerable time as artworks tour from venue to venue, or as a series of related artworks explores a common approach or genre, providing repeated opportunities to study how they are designed and delivered to be experienced by large numbers of users, and to chart how they evolve or adapt to varied settings. However, such projects are also distinctive from other research in the wild, or indeed from other approaches in HCI, in that they are artist-led (rather than user-led or researcher-led), meaning that they originate with the creative vision of artists, with researchers helping realize the vision and studying the resulting production.

In the article, we explore this notion of artist-led in the wild research in depth, articulating its distinctiveness, wildness, process, the opportunities it brings, and the challenges it raises. Our approach is to offer a historic and reflective account of a series of interleaved projects that have unfolded over a period of over fifteen years. These are centred around the work of the Mixed Reality Laboratory at Nottingham and its involvement with a series of artists including Blast Theory and Brendan Walker as discussed in detail below, but also others, since 1996. Although diverse in their interests and practices, these artists share a common interest in live performance, drawing heavily on theatrical traditions in their work. Given the breadth of HCI's growing engagement with artists, and certainly the vast scope of the arts beyond HCI, we refer to this style of work as being "performance-led" throughout the remainder of this article so as to make clear its grounding in a particular artistic tradition.

By adopting a long-term historic view of how this particular set of artistic collaborations unfolded, we are not only able to chart the evolution of a series of unusual projects that have influenced HCI, but also to reveal complex relationships between artistic practice, studies in the wild, and wider theoretical generalizations that, we argue, lie at the heart of this approach.

\section{WHY DO PERFORMANCE-LED RESEARCH IN THE WILD?}

We first ask why engage with artists as part of research in the wild? As researchers, we offer three primary motivations. The first arises from the creativity of artists. Artists' uses of emerging technologies are often highly innovative and unusual, stretching the technology in unforeseen ways, highlighting new design values and approaches that are sometimes contrary to received wisdom in HCI (e.g., ambiguity or discomfort as we discuss later), and opening up new areas of application. In short, artists may be unusually imaginative and provocative with their uses of technologies. Second, the public deployment of artworks offers a test-bed for putting emerging technologies into the hands of users in a "realistic" situation, meaning a situation in which the technology needs to be made to work and is treated in some sense a professional product this is the "in the wild" aspect of the approach that we discussed previously. The third motivation concerns the importance of artworks to enriching our cultural life within society. For us, art is an important use of computers in its own right and projects should legitimately serve as art as well as research. Indeed, some of the challenges that we describe later arise from the need to balance both. Of course, artists may also benefit from engaging with researchers, not least through insights into how audiences experience their works, but also through exposure to emerging concepts and technologies as well as research processes.

\section{PROCESS OF PERFORMANCE-LED RESEARCH IN THE WILD}

There is of course a long history of interactive art as well as using computers to create more traditional (i.e., noninteractive) artworks dating back to the earliest days of computing. Indeed, the rich history of interactive and digital art is extensively documented in numerous books (e.g., Candy and Edmonds [2002], Dixon [2007], and Wands [2007] and curated and presented by cultural institutions such as the Ars 


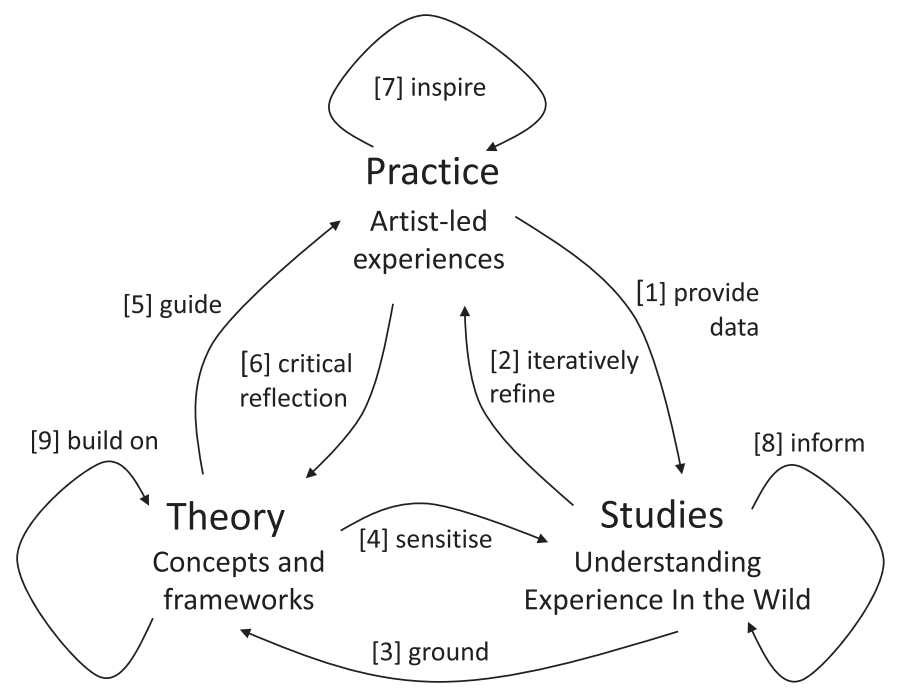

Fig. 1. Overview of performance-led research in the wild.

Electronica [2012] and ZKM [2012]. There has also been considerable interest in interactive art within the computing community for many years, for example popular arts tracks that run alongside conferences such as SIGGRAPH and Multimedia. There is also an established history of arts-related research within HCI, from the Creativity and Cognition conference series to specific discussions of art in relation to ambiguity [Gaver et al. 2003], interpretation [Sengers and Gaver 2006], aesthetics [Graves Petersen et al. 2008], sustainability [DiSalvo et al. 2009], and also the role of the artist-researcher [Taylor et al. 2011]. Against this broad backdrop, what we are talking of here is a specific orientation towards arts-related research within HCI; one that relates to other approaches, but that also has its own distinctive "in the wild" characteristic that we explore in this article.

Earlier work has already defined the approach of performance-led research in the wild as involving a triangle of distinct but interleaved activities that inform one another in various ways [Benford et al. 2011]. We reproduce this in Figure 1, but also extend it with three new relationships (the ones labeled [7], [8] and [9]).

The first of these activities is practice in which artists and researchers work together to realize artworks that are ready to be shown in, and frequently tour though, public venues. The artists typically have a vision, which may be more or less well formed at the start, of what the artwork is to be, and the main role of the technology-oriented researchers is to help them realize the idea, ideally to the point where it can tour independently with minimal further support. In practice, the process of creating the artwork is frequently iterative, with both artists and technologists contributing ideas to the emerging work. However, the essential nature of this activity is that it is driven by the artists, follows artistic practice, often runs to tight production deadlines, and is ultimately deployed as a professional and public artwork.

The second and quite different kind of activity involves studies of the artworks once they are deployed. This tends to be led by the researchers who may employ a variety of methods to document and analyze the experience of the artwork from various perspectives. Common among these has been the use of ethnography, and in particular ethnomethodology [Garfinkel 1967], to produce "thick descriptions" of how the work unfolds, drawing on observation backed up with interviews and potentially drawing 
on video documentation as well as system logs that may provide additional insights into participants' interactions [Crabtree and Rouncefield 2012]. The resulting thick descriptions may focus on the experience of selected participants as they engage with the work, as well as on the rationale of the artists and the work that they do to deliver the experience. However, other approaches may also come into play, including those from the humanities, for example, documenting and describing the work as part of performance and theater studies.

Rogers has argued that studies of experiences in the wild should generate "wild theories", and that these might take a range of forms from overarching paradigms, through theories and models, to frameworks of concepts, and might also range from being generally descriptive of a phenomenon to highly prescriptive for future design [Rogers 2011, 2012]. We are in agreement with this sentiment, and generalizing theory is a core activity within our research in the wild. For us, theory can take a variety of forms, initially involving new concepts to explain phenomena, but more recently extending to broader frameworks of concepts that also point towards new designs. One important role for our theories is to act as boundary objects [Star 1989] between the arts and HCI communities, or between the artistic-HCI community and other HCI communities, distilling the craft knowledge that artists learn over many years of experience into some general principles that can guide others in how to make similar experiences or that may provoke us into new ways of thinking about our interactions with computers [Benford et al. 2009]. This is not to suggest that an HCI researcher can become an artist merely by reading a conceptual framework, but rather that some of the techniques that are present in interactive art may be useful for designing others kinds of experience, for example cultural visiting or entertainment experiences. A second role of conceptual frameworks is to support researchers with "sensitizing concepts" that can guide the analysis of other experiences [Bowen 2006]. Either way, the generation of theory is a distinctive and important form of activity within the overall approach.

In our experience, the generation of theory typically involves the repeated construction and population of taxonomies and dimensions of concepts in an attempt to find some minimal set of abstractions that appear to cleanly, and perhaps minimally, express the important facets of several artworks as revealed by a series of studies. This might potentially involve the use of grounded theory in which data are systematically coded and then recoded as the researchers moves their attention back and forward between data and concepts [Glaser and Strauss 1967] although in many of the following examples, studies serve to inspire and illustrate concepts or dimensions and taxonomies act as high-level "codes" rather than researchers undertaking detailed coding of data.

Such theorizing can be distinct from studies in several regards. First, the orientation of the researchers (and consequently the people involved) may be quite different; ethnomethodologists in particular tend to eschew the theorizing that is associated with other approaches, including other forms of ethnography [Crabtree et al. 2009]. Thus, while our overall approach is able to accommodate ethnomethodological studies and theorizing, these should not be seen as the same activity - they may well be carried out by different people and at quite separate moments. Thus, there is a loose, but still vital, coupling between studies and theory. However, there are also cases where an individual researcher may shift between the different perspectives, as in the case of grounded theory approaches. Indeed, there is also the phenomenon of the "artist-researcher" in which a single individual moves between all three perspectives, an approach that may become more prevalent if HCI's interest in the arts continues to expand and artists are drawn to undertake interdisciplinary Ph.Ds, a trend we are already seeing in our lab. Such cases in which artists are practicing, studying and theorizing may require 
them to be able to carefully shift perspectives, or perhaps adopt alternative stances as recently described in the approach of "design from within" [Taylor et al. 2011].

Second, theories may emerge from a series of studies of various artworks over a longer timeframe than the studies themselves.

The three key activities of practice, studies and theory that we have just discussed inform one another through the nine key relationships (labeled in Figure 1).

(1) Performance-led practice can provide data for studies, or more precisely, can provide an opportunity to gather data from "the wild" of public performance;

(2) Studies may help iteratively refine the artwork as part of a process of iterative design;

(3) Studies can ground theory initially raising issues that suggest more general treatments, or contributing examples to illustrate or text theoretical concepts;

(4) Theory can sensitize studies; more specifically they can provide sensitizing concepts through which to examine or analyze data as noted previously;

(5) Theory can also guide practice, distilling artists' "craft knowledge" into guidelines that can be used by other artists or perhaps practitioners in other fields;

(6) Artistic practice can directly inform theory through the processes of critical reflection as widely practiced within the arts and humanities in which potentially wide ranging comparisons of a genre or history of artworks leads to new theoretical insights.

Our final three relationships - added for this article - recognize the direct self-reflexive relationships between the three activities.

(7) Artistic practice often directly inspires further practice. Indeed, it is common for artists to gradually develop a theme, genre or style over many years or practice.

(8) Studies can of course directly inform further studies that might follow up on an open issue or question in greater depth.

(9) Finally, theory can directly build on other theory, for example integrating existing concepts into an overarching framework, or in turn, breaking down and refining concepts into greater detail.

Thus, adopting this broad perspective, performance-led research in the wild would appear to be a complex process that draws on a wide set of research skills, from technical research and implementation, to ethnography, to theorizing. While, there may be individuals who can fluidly move between all of these different perspectives, it is perhaps more typical for the overall endeavor to involve larger teams of researchers, with key individuals engaging at different points. Finally, in the same way that HCI researchers may contribute artistic ideas, so the artists may also contribute to studies and theory. Indeed, many artists routinely engage in their own artistic research process to gather ideas and explore new techniques outside of making a specific artwork. In order to further explain how this approach has emerged over 15 years of experience and to explore how the various relationships work in practice, the following section now presents a detailed historical account that draws on key examples to illustrate the complex interrelationships between artistic-practice, studies and theory.

\section{WHERE IS “THE WILD” IN OUR APPROACH?}

While the scope and nature of research in the wild is still emerging, perhaps the clearest articulation to date has been offered by Rogers [2011, 2012] who identifies several distinctive characteristics of the approach. Rogers argues that research in the wild is not only about studying technologies in situ, but also involves designing, prototyping and implementing them so as to understand how people react to them, change them and integrate them into their everyday lives. She emphasizes a focus on 
"everydayness" and of experiences that take place outside of the laboratory, are not scaffolded, and allow people to appropriate technologies for themselves.

It is interesting to compare our approach with Rogers' definition. We are primarily concerned with collaborating with artists to create cultural experiences that are deployed "for real", typically in a bona fide cultural venue such as a gallery, theater, theme park or festival, to be experienced by the public who should see them as cultural artifacts rather than laboratory prototypes. Of course, artworks can exist in all manner of settings, including laboratories; our point here is that these novel experiences should be framed or recognized as artworks by a community of artists, curators, promoters, critics, public audiences, and so forth. However, it is less clear at first glance to what extent the experiences can be considered to be everyday. While going to cultural venue is a broadly everyday experience for many, the specific experiences that we describe in this article are far from everyday, but rather tend towards the unusual and extraordinary. However, we would argue that it is a normal part of many people's lives to visit places such as galleries, theme parks and festivals in order to deliberately seek out extraordinary experiences. In other words, even very unusual experiences have a quality of everydayness to them if they are seen as being genuine within these kinds of cultural settings. More problematic are the matters of scaffolding and appropriation. The experiences that we describe below are in fact highly orchestrated (i.e. scaffolded) and most are generally not open to appropriation by their audiences. However, it is the artists who are doing the scaffolding here as an essential and normal part of delivering the experience. Indeed, the cultural venues of galleries and so forth are very much an everyday in the wild setting for the artists in the sense of being a normal and expected place of work. In short, we maintain that even though the experiences we discuss are often unusual and even extreme, they still constitute research in the wild in that they operate as recognized cultural experiences.

\section{UNPACKING PERFORMANCE-LED RESEARCH IN THE WILD}

Our interest in performance-led research in the wild initially grew out of a series of projects in the mid-1990s to explore the potential of collaborative virtual environments to enable new forms of performance and entertainment. While our early attempts to stage so-called "inhabited television" shows in virtual worlds were interesting from a technical perspective [Benford et al. 2000], they quickly taught us how difficult it is to create engaging experiences for a public audience, leading us to the realization that we needed to engage in a more performance-led approach that would give free reign to artists to create professional quality experiences. This led to collaborations with various artists groups from 1996 onwards such as Blast Theory, Brendan Walker, Active Ingredient and others, yielding a series of public performances and installations as well as a number of academic papers based upon these.

It is not necessary to document the full history of this work in this paper; a more detailed historical perspective can be found in Benford et al. [2011]. Rather, in the following, we focus on a selection of landmark projects delivered in collaboration with two particular artists, Blast Theory and Brendan Walker, that between them illustrate the approach of performance-led research in the wild in some detail. Figure 2 provides a chronological overview of our selected artworks alongside some key papers - both studies and theories - arranged along a timeline from 1997 to the present. The following paragraphs describe this history, focusing on the complex relationships that emerged between these different activities and explicitly relating them back to the relationships labeled in Figure 1. In order to bring some coherence to what is a complex picture, this section is structured around four key phases that illustrate how the relationships between practice, studies and theory gradually evolved. However, it needs to be understood that this is something of a convenience for presenting the story in this 


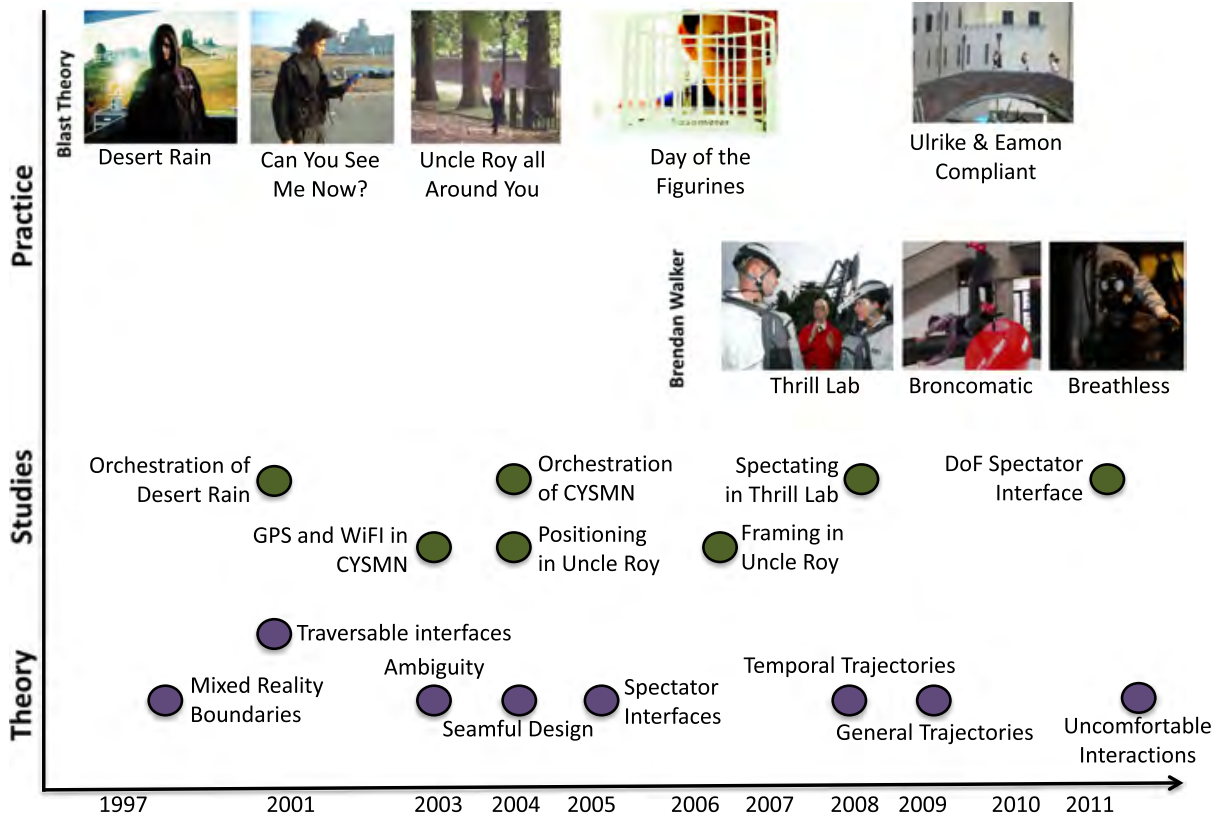

Fig. 2. Chronology of selected artworks, studies and theories that feature in this article.

article, and that in practice the projects, studies and theories overlapped in time to a greater extent than can be shown here.

\subsection{Desert Rain, Boundaries and Orchestration}

How a First Performance-Led Project Related to Theory and Studies. We first met the artists Blast Theory in 1996. At that time, we were exploring the idea that an interface to a virtual world could be thought of as a permeable, bidirectional, and potentially traversable "mixed reality boundary" between the physical and virtual [Benford et al. 1998] that would potentially allow participants on either side to see - and ultimately to cross over into - the other. On hearing of this idea, the curator of Nottingham's NOW arts festival introduced us to Blast Theory who, as part of a residency, were experimenting with projecting images into a fine water spray into and through which they could then physically move. Following an initial joint workshop, the artists proposed the idea that ultimately developed into Desert Rain, a performance work in which six players at a time are sent on a mission into a shared virtual world that is projected onto six "rain curtains", large screens made of a fine water spray through which actors, and ultimately the participants themselves, could pass to find themselves in a further physical set. Following a year of development, the first public version of Desert Rain was staged in Nottingham in 1996, was subsequently refined over further performances, and then toured internationally to over fifteen venues worldwide, receiving considerable critical acclaim including a nomination for a UK BAFTA award. Early design work on the rain curtain featured in a conceptual paper on "traversable" boundaries [Koleva et al. 2000]. However, the initial performances of Desert Rain were also studied by ethnographers from Kings College London leading to a paper at CHI 2001 that documented its design and unpacked the various ways in which the artists orchestrated the experience from behind the scenes in order to deliver maximum impact to the participants within a tightly constrained performance schedule [Koleva et al. 2001]. 


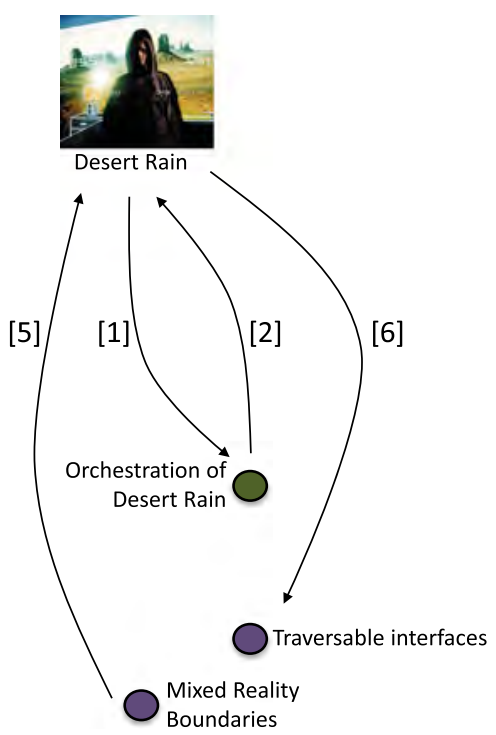

Fig. 3. The artwork Desert Rain related to theory and studies.

The success of Desert Rain as both a creative and research endeavour established several important elements of the (then nascent) process of performance-led research in the wild. First, it was clearly performance-led, underpinning its success and establishing its credibility to tour to major arts festivals and venues where it could be experienced by (paying) public audiences. This then provided opportunities and data for ethnographic study (relationship 1) which in turn fed back into subsequent iterations of the work as it developed over early performances (relationship 2). This early experience also demonstrated an iterative relationship with theory. The concept of Desert Rain was in part inspired (relationship 5) by the existing theoretical concept of mixed reality boundaries, and subsequently fed back into this by demonstrating an unusual approach to creating a traversable boundary. Thus, even at this early stage, there were strong hints of complex relationships at play between performance-led practice, studies in the wild, and theoretical concepts as shown in Figure 3.

\subsection{Can You See Me Now?, Uncle Roy, Seams and More Orchestration}

Two related artworks, a series of interlinked studies, and a further theoretical concept (Figure 4).

Can You See Me Now? and Uncle Roy All Around You were two subsequent and related projects with Blast Theory that explored the core dynamic of mixing online players with those on the streets of a city. The premiere of Can You See Me Now? Took place in Sheffield in the UK in 2001 and the work rapidly evolved to tour to many cities worldwide. Performers ran through the streets of a city in order to chase online players who steered their avatars through a virtual model of the same city. Performers' positions were tracked using GPS and were streamed to the online players alongside an audio stream of their communication and ambient background noise, enabling the online players to tune into their experience of the city.

Inspired by this, Uncle Roy All Around You, further extended the core dynamic (relationship 7) by placing the public on the city streets as well as online and encouraging online players to help guide street players to Uncle Roy's office, a real office in the city, and from there to a waiting car to be interviewed by an actor. The design of both 


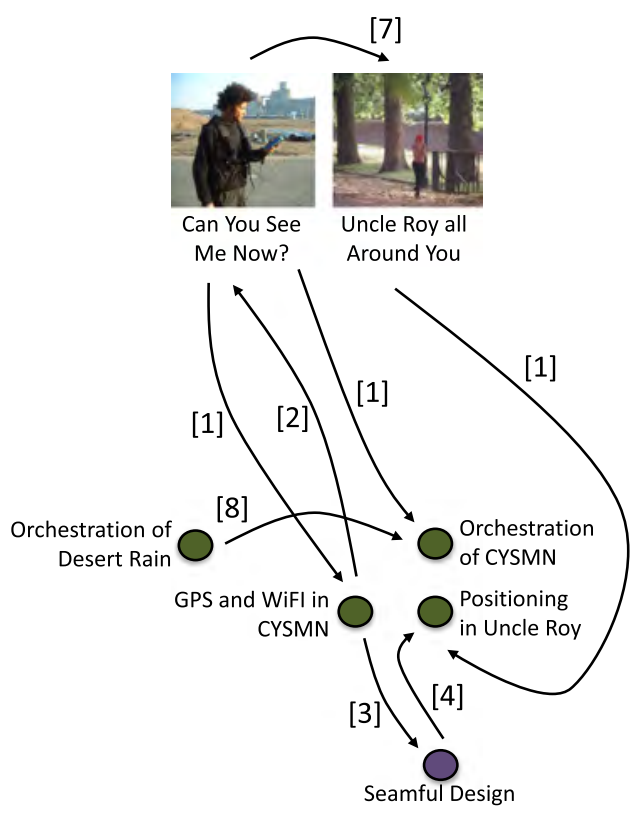

Fig. 4. Multiple artworks now relate to multiple studies.

works was performance-led, although grounded in a growing mutual understanding of the overlapping interests of the artists and researchers in new ways of connecting the virtual to the physical. As with Desert Rain before, evidence for the artistic credibility of the works can be found in extensive touring as well as critical acclaim; Can You See Me Now? was awarded the 2003 Prix Ars Electronica Golden Nica for Interactive Art, while both works were nominated for UK BAFTA awards.

Both were also subject to ethnographic study, leading to a series of research papers. The study of Can You See Me Now? showed us the prevalence of gaps in the coverage of the underlying positioning and communication technologies, and their impact on the experience, revealing the various ways in which the performers and supporting orchestration team worked together to cope with these [Flintham et al. 2003] (relationship 1) which in turn fed back into new online visualizations, orchestration tools and processes and ultimately a reimplementation of the game using GPRS instead of WiFi (relationship 2). Along with other experiences, this study fed into Galani's and Chalmers' theoretical account of "seamful design" [Galani and Chalmers 2004], which, in turn, helped ground their subsequent development of new experiences such as "seamful games" that actively exploited seams in the technological infrastructure to create new game mechanics (relationship [3] and ultimately [6]). A subsequent ethnographic study of Uncle Roy All Around You employed this idea of seams as a sensitizing concept (relationship [4]), contrasting participants' use of self-reported positioning with the earlier experience of GPS in Can You See Me Now? [Benford et al. 2004]. Other examples of this relationship also came into play as the corpus of artworks and studies began to grow. For example, the theoretical discussion of orchestration from Desert Rain was revisited and extended in a separate study of Can You See Me Now? [Crabtree et al. 2004] (relationship 8), and also featured in studies of Uncle Roy All Around You [Benford et al. 2006] and subsequent works. Several of these papers also featured attempts to articulate more practical guidelines to the designers of similar experiences such as games, performances, and museum and gallery installations 


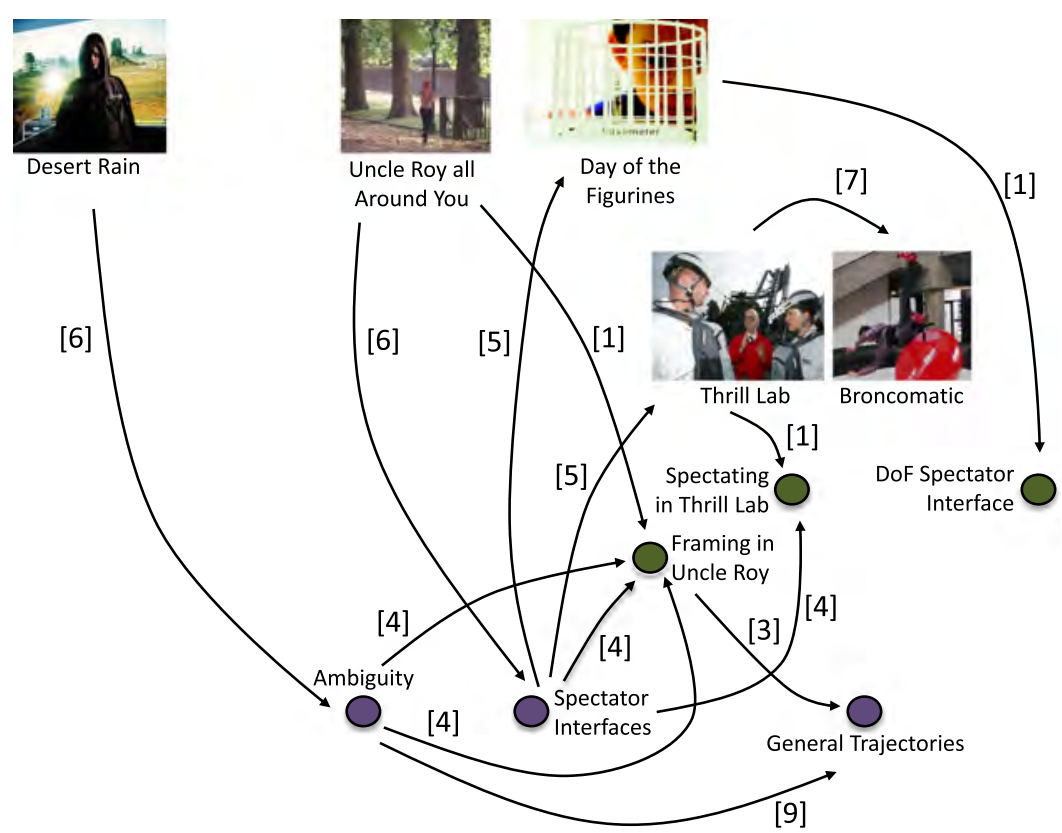

Fig. 5. An evermore complex web of relationships between practice, studies and theory.

(relationship 5), including proposing general-purpose authoring and orchestration tools, for example, the idea of extending location-based authoring tools that overlap trigger zones on maps with an infrastructure visualization layer that would directly reveal likely seams to designers [Oppermann et al. 2006]. In short, by this stage, we were seeing a complex series of interrelationships in which multiple artworks enabled a series of related ethnographic studies that in turn, informed new theoretical concepts.

\subsection{Ambiguity, Spectating, Day of the Figurines and Thrill Laboratory}

In an increasingly complex web of relationships, critical reflection informs new theoretical ideas, a process that underpins further practice (Figure 5).

Although, at first sight, the move from practice to studies to theory is an obvious, perhaps even expected, route around our triangle - one makes something, studies it in the wild, and derives a theoretical principle from this - it is far from being the only one. In particular, we experienced a powerful and direct connection between artistic practice and theory through a process of critical analysis and reflection. 2003 saw the publication of a paper that directly drew on a range of examples from the history of art, including Desert Rain, to make a theoretical argument for the constructive use of ambiguity in HCI to provoke interpretation [Gaver et al. 2003]. This article did not draw on the ethnographic studies of Desert Rain, but rather engaged with the work through a process of critical reflection (relationship 6). Not long after and in a similar vein, 2005 saw the publication of a theoretical account of how to approach the design interfaces for spectators in terms of revealing various combinations of manipulations and effects, again derived from a critical analysis of various artworks including and Uncle Roy All Around You [Reeves et al. 2005]. Both the ambiguity and spectating papers also attempted to articulate general design guidelines or tactics to support the design of future experiences (relationship 5) while at the same time providing sensitizing concepts for ethnographic studies (relationship 4). As an example of the latter, a subsequent account of Uncle Roy All Around You drew on both ethnographic 
data (relationship 1) and the two concepts of ambiguity and spectator interfaces (relationship 4) to provide an account of how Blast Theory created an ambiguous "framing" of the relationship between participants and bystanders on the city streets [Benford et al. 2006]. In this way, theoretical concepts such as ambiguity and spectating that were derived from critical reflection, become tied back into studies.

Emerging notions of spectator interfaces also influenced a series of new practice projects (relationship 5). One of this was a further Blast Theory project, Day of the Figurines [Flintham et al. 2007], that featured a consciously designed "spectator interface" to "frame" participants initial introduction to the experience. Second, we produced the first in a series of projects with our second featured artist in this paper, Brendan Walker. He first approached the Mixed Reality Laboratory with a specific idea to stage a series of performances at the London Science Museum's Dana Centre in which personal data including video, audio, heart-rate and galvanic skin response would be captured from the riders of various amusement rides, streamed over a wireless network, and displayed to a watching audience alongside an interpretation from various experts. While primarily performance-led, this idea resonated strongly with our theoretical work on spectator interfaces, which could be considered to have at least in part guided its ultimate shape (relationship 5). Ethnographic study of these public events (relationship 1) revealed complexities in the relationships between riders, the audience and the ride operators, raising implications for the selective revealing of personal information and further grounding and extending the theory of spectator interfaces (relationship 3) [Schnädelbach et al. 2008].

This first project with Brendan quickly led to further performance-led practical explorations of engaging spectators with rollercoaster rides and other thrilling experiences including a series of trials at Alton Towers amusement park in the UK and related articles for primetime television. This growing interest in using biodata to enhance the spectator experience of thrill rides ultimately extended to the design of the rides themselves, inspiring the Broncomatic, a breath-controlled bucking-bronco ride in which the rider's breathing partially drove the movements of the ride, requiring them to control their own bodily response to a ride that was physically pushing back at them [Marshall et al. 2011].

These theoretical concepts of ambiguity and spectator interfaces were also employed and extended by others. Sengers and Gaver [2006] extended the notion of ambiguity with further consideration of interpretation and provocation in relation to interactive art, while Aoki and Woodruff [2005] applied the concept of ambiguity to 'saving face' during personal communications. The notion of spectator interfaces informed (and was informed by) the work of Sheridan [2006] and Reeves [2011] who have provided extensive accounts of the complex relationships at play between performers, spectators, audiences and bystanders, and subsequently informed the recent work of Koppel et al. [2012] colleagues in studying how people interact with series of chained displays in public settings.

\subsection{Day of the Figurines, Trajectories and Uncomfortable Interactions}

The construction of a more overarching theory from multiple examples of practice, studies and theoretical concepts (Figure 6).

So far, we have shown how, over a period of ten years, we established evermore complex and iterative relationships between performance-led practice, studies of these artworks and theoretical concepts. As the corpus of projects and studies grew, so it became possible to undertake deeper theoretical reflections across a larger corpus of work. Blast Theory's 2006 project Day of the Figurines proved to be an initial catalyst for this more overarching style of theoretical work. This was a slow text messaging game for mobile phones in which players experienced a day in the life of a fictional 


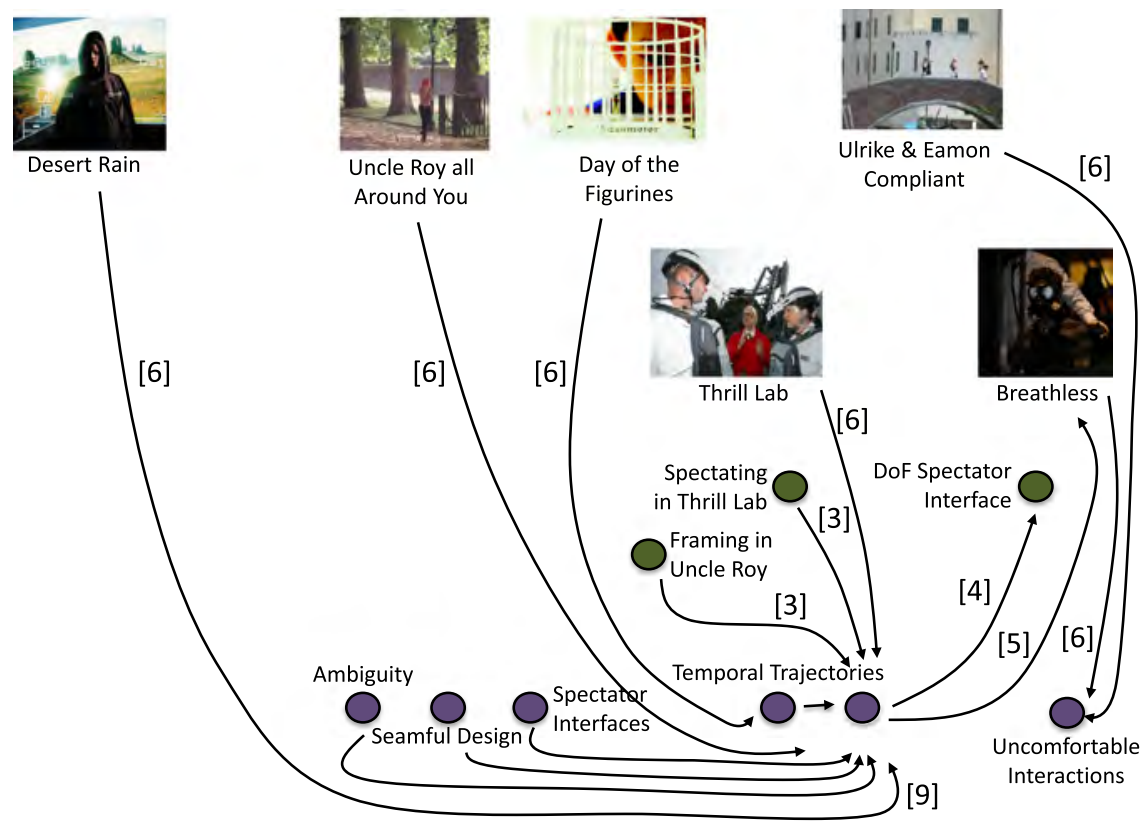

Fig. 6. Practice, studies and theories inform more overarching theories.

town spread over a month of their actual lives. While much of the experience involved sending and receiving text messages as the player went about their daily life, the initial introduction to the game involved engaging with an unusual spectator interface (as noted previously) in the form of small physical figurines that were moved across a large tabletop display. Studies of Day of the Figurines (relationship 1) made use of ethnomethodologically informed ethnography, but also involved a researcher from the field of Performance Studies analyzing the work from a dramaturgical perspective. While previous works such as Desert Rain and Uncle Roy All Around You had been subject to artistic analysis and reflection (relationship 6) by humanities scholars, this study was different in that the ethnographer and humanities researchers drew directly on a common corpus of data - video recordings, interviews, and logs of text messages but analyzed them from quite different perspectives. Indeed, the ethnographer and humanities scholar occasionally used the same research tool, the Digital Replay System [Greenhalgh et al. 2007], to explore and annotate this common data as part of their individual studies. This use of a shared tool to analyze a common dataset, but from radically different disciplinary perspectives, led to a series of papers that discussed a variety of theoretical concerns from now familiar ones such as orchestration and spectating [Benford et al. 2011], to new ones including discussions of temporal structure and especially slowness [Giannachi and Benford 2008].

These various artworks, studies and concepts also inspired the new theoretical idea of describing complex interactive performances in terms of interleaved trajectories. The first presentation of this new idea assumed a relatively narrow focus, discussing trajectories through time, largely based on a critical reflection Day of the Figurines [Benford and Giannachi 2008] (relationship 6). However, it soon became apparent that there were much wider notions of trajectories to be found in many of the projects we had worked on, going right back to Desert Rain, as well as in previous studies on installations in museums and galleries by other researchers, including a series of studies of museum interactives by Vom Lehn et al. [2001] and of interactive artworks 
by Costello et al. [2005]. This led to a much broader theory of trajectories through extended user experiences that aimed to provide a comprehensive account of how mixed reality performances (as we then named this emerging genre of artistic practice) are designed and experienced. This theory argues that such performances, and possibly other kinds of experience too, involve three fundamental kinds of trajectory canonical (the plan or script), participant (the actual experience of a given individual) and historic (recounting of this experience in some way) and that, by thinking in terms of trajectories, analysts and designers can gain new insights into designing the social aspects of experience, managing key transitions, and the role of orchestration. The first articulation of this theory drew on the examples of Desert Rain, Can You See Me Now? and Fairground: Thrill Laboratory [Benford et al. 2009], (relationship 6 again), while the later book-length treatment drew on a far wider variety of projects and studies from the preceding fifteen years. Moreover, the theory also consciously drew on several previous theoretical concepts (relationship 9) as well as studies (relationship 3) [Benford and Giannachi 2011].

Once set in motion, this loop between practice, studies and theory seems set to continue, with each feeding into the other. As the most recent example, the theory of trajectories has underpinned the latest Thrill experience, Breathless in which riders controlled a powered swing using their breathing (while wearing gas masks), but also passed through a clear trajectory from initially watching another rider, to being a rider, to ultimately controlling a further rider. In turn, critical reflection on Breathless and a recent Blast Theory work, Ulrike and Eamon Complaint, have inspired and illustrated a new theoretical idea concerned with the deliberate use of discomfort to help create experiences that are entertaining, enlightening or socially bonding [Benford et al. 2012].

This brings us to the close of an account of how the approach of performance-led research in the wild evolved and the kinds of activity that it involves. What we have shown here is how our approach to performance-led research in the wild interleaves three core activities - practice, studies and theory - but also how, over time, these feed into one another in complex ways across multiple projects. It seems that "research in the wild" can involve a great deal more than deploying and studying a prototype outside of the laboratory.

\section{THE CHALLENGES OF PERFORMANCE-LED RESEARCH}

Having explored performance-led research in the wild in some detail, we now reflect on the key challenges that it raises so as to guide other researchers who might wish to pursue this approach. We begin with specific challenges associated with each of the three core activities before ending with some overarching challenges for the overall approach.

\subsection{Practice Challenges}

Contrasting Approaches to Development. In our experience, artists and technologists can have quite different rhythms of development. In some projects, researchers initially struggled with the tight and short-term production schedules; that is the idea that a working experience has to be put in front of a public audience by a strict deadline. In particular, there is often a need to jettison interesting, but only partially working, ideas in favor of a stable, if simpler, experience. We have seen occasions where tools and interfaces that were developed over several months were jettisoned close to the first performance and never subsequently used. Research demos tend to have a relatively relaxed delivery compared to a performance that must go live at a certain time and deliver a reliable throughput of participants. Conversely, while artists have often been involved in developing some software for the experiences, 
they tend to have relatively short-term focus and a less structured approach to development. There may be intense activity as each performance approaches, but less time to develop scalable and reusable platforms and tools in the gaps between, often because other projects then come into sharp focus. The differences in development approach may be attributable to the underlying values or standards by which products are assessed, the finish and feel of the artistic experience at the interface versus the structure and reusability of the underlying platform. These distinctions are by no means universal or insurmountable, but our experience is that it takes some time and mutual understanding to build an effective development team, and the first performance developed by a new team has the potential to be an especially fraught affair. It is especially important that HCI technologists understand the rigors of live performance as early as possible and that teams contain a balance of experience.

Touring. A second challenge concerns the demands of touring. As noted earlier, a new work may be refined and stabilized over several initial performances, typically around three in our experience, that may take place in different cities and possibly on different continents (Day of the Figurines, for example, was developed and refined over outings in London, Barcelona, Berlin and Singapore). Each performance may involve a large team being onsite for several days, possibly more than a week. The first outing of Uncle Roy All Around You, for example, involved a team of about ten onsite in London for nearly two weeks, and working long days during this time. It is important not to underestimate the considerable strain that this places on researchers as well as the expense involved. The artists will then most likely wish to tour the work after the initial development phase. Desert Rain, Can You See Me Now?, Day of the Figurines, and Eamon and Ulrike Compliant all enjoyed lengthy touring lives, while the Thrill Laboratory team subsequently engaged with a series of television productions in the UK and US. It is therefore vital to plan a handover process so that the artists are ultimately able to tour the work without the research team being present. For example, we ran a training workshop for young artists to learn how to run Can You See $\mathrm{Me}$ Now?, both to help them understand how such works are delivered, but also to enable them work with Blast Theory during subsequent touring.

Documentation. Finally, we note the challenge of documentation. The experiences presented in this article are both ephemeral and sufficiently complex that they can be difficult to convey in words. Both artists and researchers therefore require extensive documentation, often in the form of a produced video, so that they can show the work to their respective communities. Indeed, one of the great benefits of working with professional artists can be the quality of the video documentation that they produce, which tends to have high production values. However, documentation is expensive and has to be planned for. Furthermore, the different audiences demand somewhat different approaches. The ideal research video tends to be a couple of minutes in duration (so as to comfortably fit into a conference presentation) and be fairly didactic in approach. In contrast, artists documentation may typically run between five and ten minutes, be far less didactic, and may also quite often contain themes and language that may challenge HCI and other technical conference committees. It is therefore important to plan from the outset for multiple video edits, or to produce a video that contains several parts - for example, the Uncle Roy All Around You Video begins with a relatively didactic couple of minutes before moving into a longer more experiential sequence.

Looking back, the challenges raised in this section feel very pragmatic, perhaps even somewhat obvious. Of course, it is difficult working to a tight production and touring schedule. Obviously we need good video documentation. But these are important nonetheless. The combination of these factors lends performance-led research in the wild a very distinctive feel and rhythm that may be challenging to learn and follow. 


\subsection{Study Challenges}

A different set of challenges arises when studying artworks in the wild.

Observing Participants. First, it can be challenging to observe participants and record data as part of fieldwork. The issues of studying mobile and ubiquitous experiences are well known [Crabtree et al. 2006] and include being able to follow participants, observe their interactions with collections of small devices, and capture their rapidly changing context. These are compounded in many of our cases by the complexity of the experiences, perhaps involving multiple online and "on the streets" participants, combinations of digital media and live action, and in the case of Day of the Figurines, an extended timescale with the experience slowly unfolding over a month. Moreover, key locations may be relatively inaccessible, for example the limousine in Uncle Roy All Around You, the large rides in Thrill Laboratory, or in the case of Blast Theory's Rider Spoke (not described in this article), the challenge of observing cyclists exploring a city at nighttime. Not only do these experiences amplify familiar problems, but they also introduce new ones. One ongoing tension throughout our history of projects has been balancing the ethnographers' desire to follow people through the experience with the artists' feelings that this may compromise experiences that are designed to be highly personal and subjective and rely on moments of isolation and deep engagement. Consequently, artists have often balked at the idea of ethnographers hanging around at the entrance to a work and accosting paid up members of the audience. Of course, there are many challenging settings for ethnography, and ethnographers become skilled in negotiating access. However, this is often facilitated by a process of prolonged immersion, which is generally not an option here, and so we require other strategies including explicitly recruiting participants to take part (often paying for their tickets) or, in the case of a long experience such as Day of the Figurines, the ethnographer directly participating in the experience alongside family members [Tolmie et al. 2008].

Capturing the Artists Intent and Audience Experience. Understanding the experience of the audience is only a part of the overall picture; it is also desirable to understand the artists' rationale and the work they do to "make the experience work". Indeed, we have seen that the very earliest studies, from Desert Rain onwards, strongly focused on the behind the scenes "orchestration work", perhaps in part because the setting of the artists "control room" is relatively easy to observe, but perhaps also because of a strong resonance with studies of air traffic [Bentley et al. 1992], London Underground [Heath and Luff 1991] and other control rooms in CSCW and HCI . However, Can You See Me Now? And Uncle Roy All Around also involved orchestrators working on the streets, for example finding participants and solving their problems on the sport, reintroducing the familiar problems of observing mobile experience. The study of Day of the Figurines extended this focus to also include the artists' rationale, documenting in detail their motivation and detailed choices in designing its spectator interface [Benford et al. 2011].

A further complication arises from the iterative development process described earlier as a work tours to its first few venues. Studying the premiere performance is undoubtedly useful as it is likely to identify a wide range of problems and feedback into further development of the work. However, subsequent performances may be quite different in terms of structure and processes and certainly in terms of smooth operation once the work has bedded in, requiring ethnographers, like developers, to engage with the touring process.

The challenge of observing complex interactive experiences is leading ethnographers to make increasing use of datalogs, alongside video recordings and field notes, in an 
attempt to piece together a holistic picture of an experience. This idea has become sufficiently commonplace that specialist tools have appeared to support ethnographers analyzing and synchronizing field notes with multiple data sources, for example, the publicly available Digital Replay System (DRS). Indeed, DRS was used to support several of the studies mentioned previously including Uncle Roy All Around You and Day of the Figurines, both of which involved analyzing fragments of video alongside system logs of reported positions and messages exchanged by participants.

\subsection{Theory Challenges}

We have seen how theories can be underpinned both by studies but also by direct analysis of the artworks themselves. We have also seen how some recent and broader theories refer to multiple artworks, including ones from the distant past (e.g., trajectories referring back to Desert Rain). Conducting such long-term theoretical work requires access to the documentation of these works and possibly also to the data from earlier studies, which leads us to the major and unsolved challenge of archiving.

Archiving. The importance of properly archiving artworks is fundamental to arts and humanities scholars. An archive systematically collects and preserves a wide variety of documentation of a particular artwork or artist in a way that can be accessed by a variety of scholars and students for research and teaching too. Archives are essential to supporting the critical reflection that ties a body of artworks into a new theory to the point where arts and humanities funding bodies routinely fund the generation and maintenance of archives as well as investigations of new archiving approaches and technologies. In contrast, HCI is much less familiar and less bothered with archiving its experiences for future study (although historical exhibitions of interface devices at recent $\mathrm{CHI}$ conferences do hint at a growing interest in preserving our own history [Buxton collection 2011]). In keeping with the common practice of HCI, we did not properly archive most of the artworks described previously, and with hindsight this is probably something of a mistake as it may limit the possibilities for future and deeper theorizing by ourselves and others. Indeed, this would appear to be a fundamental lesson that HCI can learn from other disciplines. With this in mind, and inspired by the dual use of DRS by an ethnographer and performance studies scholar that we described previously, we recently undertook a project to systematically archive Blast Theory's Rider Spoke, building a repository of performance documentation, interviews with artists, and field notes, tagged with metadata to promote access [Giannachi et al. 2010]. We also allowed different researchers and students to publish their individual analyzes of the material back into the archive itself as a "historical trajectory" so that others could follow their route through the material, read their annotations and reflect on their interpretation.

From Theory to Practice. A second major challenge for theory lies in relationship [5] from Figure 1; that is, in putting theory in practice. While several of our theoretical papers have articulated guidelines for HCI practitioners, for example tactics for employing ambiguity or discomfort, there is as yet little evidence for their successful uptake. Optimistically, it may only be a matter of time, waiting for mainstream entertainment applications to emerge that mirror the artistic explorations that first inspired these concepts. But perhaps we need to do more to promote their use, teaching them to students or practitioners, even at the risk of distracting us from conducting further research? Alternatively, perhaps guidelines are not a sufficiently strong embodiment of theory. Maybe what we truly need are tools and platforms that embody these mechanisms to the level of code. The problem of transforming theory into practice is a wider one confronting HCI, one of the key conclusions reached by the recent EPSRCled international review of HCI in the UK [EPSRC 2012]. It is a difficult challenge, 
but without addressing it, the productive relationships between practice, studies and theory may not be fully realized.

\subsection{Overarching Challenges}

We conclude our discussion with several overarching challenges for the whole approach of performance-led research in the wild.

Balancing Artistic and Research Interests. One of these challenges concerns allowing for an appropriately shifting balance of control between artists and researchers so as to respect their different goals and practices. We have alluded to this when discussing software development earlier, but it is in fact a deeper problem. Our process takes the idea of performance-led practice seriously; it is the artists who take ultimate control of the form and content of the work and also where and when it is performed. After all, their artistic reputations are on the line. This has given rise to some challenging moments. For example, the decision to develop the text messaging game Day of the Figurines was a major departure from a previous plan to develop a location-based work. As researchers we were initially unsure as to the likely research value of text messaging, although ultimately this proved to be interesting and fruitful, leading us to explore the nature of episodic engagement and from there, trajectories. However, giving control to artists in this way means being willing to take risks and to create experiences for which the research questions (let alone any specific hypotheses) are not known in advance.

There are challenges for artists too. They need to spend time and effort catering to the needs of researchers, supporting user studies and also being comfortable with papers that tend to reveal the interactional challenges that were raised by their artworks and how they resolved them. While these user studies further artists' understanding of how participants actually interact in the wild, there is a danger that they may be read as criticisms of the work rather than as accounts of how it was delivered, which can be especially challenging for artists who already routinely face (occasionally hostile) criticism through arts reviews. As a further note, most of the user studies described in this article have tended to focus on the interactional challenges raised by the deploying performances in the wild, by which we mean on the mechanics of how participants interact with them. In contrast, participants' emotional or intellectual responses to the works have been relatively unexplored (although often touched upon). We highlight this as an important topic for future research, and one that can build on the foundations established by Sengers and Gaver [2006] who have begun to explore the interpretation of interactive artworks within HCI.

A Flexible Approach to Building Relationships. Ultimately, it is perhaps relationships that matter more than specific ideas. One of the important characteristics of performance-led research in the wild, other than a willingness to take risks on both parts, is a process for gradually building relationships over time, moving from initial contact, to small-scale explorations, to larger projects. In recent years, we (as a research laboratory) have extended the range of mechanisms that we use to include an ongoing residency scheme where artists can spend a few months engaged with the lab to make contacts and absorb ideas with no specific project in mind. We also now have feasibility funds to try out ideas quickly on a small scale before progressing to major performances. Key to building relationships is establishing and maintaining mutual respect, including being able to judge the other's competence: how does an artist know that an HCI researcher is good and how does the researcher know that the artist will deliver credible and interesting work?

Two further players are important in supporting this process of building relationships. First are curators. As was the case with our introduction to Blast Theory, 
curators such as festival and gallery directors play a vital role in recommending artists to researchers and vice-versa, as well as in securing early opportunities for performance. Second, are funding bodies. Our development of performance-led research in the wild has undoubtedly benefitted from various funding mechanisms over the past 15 years, especially from a variety of program launched by the combined UK Research Councils (RCUK). These have included a series of network grants that included feasibility funding for practice-led projects (rather than just for workshops as is traditional with such funding) that could cover artists' costs as well as research, for example, the Pervasive and Locative Arts Network (PLAN) [PLAN 2012] and Creator Digital Economy cluster [CREATOR 2012]. Such program have been instrumental forming and testing relationships between artists and several research labs. At the other end of the scale, major long-term initiatives such as the seven-year, eight-partner, Equator IRC that ran between 2000 and 2007 were instrumental in delivering larger projects, in particular Can You See Me Now? and Uncle Roy All Around You. Critical-mass funding with a high degree of autonomy allows for risk taking, in the sense of following an idea without having to justify specific research objectives in advance, and then being able to account for its success or otherwise later on. We believe this to be a vital aspect of supporting this entire approach. As a final note, other funders have also played their part, especially the European Union that helped fund Desert Rain and later on, Day of the Figurines and Rider Spoke, though its collaborative program. This however, has required artists to operate as Independent Research Organisations and this can be taxing both financially and administratively. However, it has also enabled industry partners to become involved too, for example British Telecom, Sony, Nokia, and Microsoft.

Ethics. Our final overarching challenge looks forward to how the approach of performance-led research in the wild may need to develop in the future by considering the issue of ethics. Fifteen years ago, at the outset of this story, there was no formal institutional ethics process governing our research. Since then, HCI has become increasingly subject to ethical processes such as the approval of ethics committees and institutional review boards, although these are by no means universal in their scope and operation. While we are not claiming to have been unduly affected by ethical processes to date, we anticipate potential challenges in carrying out this kind of research in the future, especially if HCI adopts ethical structures that were originally developed for medical research and that have shaped approaches in other disciplines such as Psychology and the Social Sciences. There is ongoing debate about the applicability of medical ethics to social sciences research [Murphy and Dingwall 2001], and so it is reasonable to anticipate challenges were they to be applied to arts-oriented research.

First, the open-ended and exploratory nature of our approach makes it difficult to articulate the specific nature of the user experience in advance, to the point where it might potentially even change significantly during final rehearsals. Understandably, ethics processes that are tuned to appraising experiments may be reluctant to sign off on highly speculative and open-ended proposals to create novel artworks from which we hope to learn something of interest. Second, artistic projects are likely to challenge existing approaching and values within HCI and open up complex new ethical issues such as the deliberate use of discomfort to entertain, enlighten and socially bond participants which at first sight would appear to fly in the face of received wisdom within HCI [Benford et al. 2012]. Not that such notions shouldn't be subject to ethical debate they most certainly should - but rather artistic works that take on challenging themes and/or involve especially provocative approaches are likely to require extensive and evolving debate. Indeed, it can be argued that one role of artworks is to provoke and 
raise such debate and to engage public audiences with it. How then can we expect an HCI ethics process to form a judgment before the debate has begun?

Third, artistic experiences may involve rethinking familiar ethical issues. What does informed consent mean when a work such as Uncle Roy is ambiguously framed to as to implicate unwitting bystanders in the performance? What does the right to withdraw mean when a participant is on a rollercoaster and unable to get off before the end of the ride no matter how scared they may feel? This is not to say that artworks are not subject to ethical constraints and regulation; they most certainly are, as artists and venues routinely have to wrestle with public safety and liability, copyright, regulation and censorship within a professional regulatory framework that governs what is acceptable to perform or show in public. And of course, this is occasionally a matter of controversial and heated public debate as some artists choose to push the boundaries of what is considered to be acceptable. With this in mind, we suggest that future research may wish to explore approaches that ensure an ethical accounting for research after the event by fostering reflections and discussions across multiple perspectives, rather than on being able to clearly judge live ethical debates in advance?

\section{CONCLUSIONS}

We end with three final questions: What is the essence of performance-led research in the wild? What is it useful for? and Might it have more general purchase within HCI?

From the beginning, we have argued that, by definition, performance-led research in the wild involves artists creating experiences that are then deployed and studied in the "wild" of public performance. However, our historical analysis in this article has shown that there is much more to the matter than this. Performance-led research in the wild appears to involve a mix of practice, studies and theory, interrelated in complex ways and potentially spanning a large body of artworks. While individual projects are undoubtedly conceived and driven by artists, they may often also be responding to previous projects or to emerging theories. Key to the approach - at least as we have practiced it - is that both artistic and research outputs must stand as professional and credible in their own rights.

We propose that the approach is obviously useful for conducting research into how interactive technologies can enable artistic installations and performances. While this may be a niche area, we maintain that it is an important one in terms of enriching people's cultural lives. The question is whether the approach has any broader merit beyond this. Might it be that only artists are able to engage in this approach because only they can deliver professional experiences within the timescales and budgets that align research budgets? Could we deliver healthcare, transportation or banking experiences using the same approach, for example?

We believe that our approach may have a wider salience to HCI for two reasons. First, there is an array of cultural experiences that are not so far removed from the kinds of artistic ones that we have discussed here. The cultural mainstream of games, museum visits, theme park attractions, marketing, film, and television all have a proven history of borrowing from artistic innovation, and it is perhaps therefore no surprise that major companies such as Sony and Microsoft have been involved in some of our projects. Second, by creating unusual experiences artists are able to surface new and potentially provocative values and issues, opening them up for wider consideration. As evidence for this, concepts such as ambiguity and spectator interfaces are now referenced by research outside of the cultural domain. We would hope that newer concepts such as trajectories and uncomfortable interactions might also find an audience in other areas of our field, further demonstrating the value of performance-led research in the wild despite the considerable challenges that it poses. 


\section{REFERENCES}

Aoki, P., and Woodruff, A. 2005. Making space for stories: Ambiguity in the design of personal communication systems. In Proceedings of the SIGCHI Conference on Human Factors in Computing Systems (CHI'05). ACM, New York, 181-190.

Ars Electronica. Website for the Ars Electronica. www.aec.at (last accessed 7/12).

Benford, S. and Giannachi, G. 2008. Temporal trajectories in shared interactive narratives. In Proceedings of the SIGCHI Conference on Human Factors in Computing Systems (CHI'08). ACM, New York.

Benford, S. and Giannachi, G. 2011. Performing Mixed Reality, MIT Press.

Benford, S., Greenhalgh, C., Reyard, G., Brwon, C., and Koleva, B. 1998. Understanding and constructing shared spaces with mixed-reality boundaries. ACM Trans. Comput.-Hum. Interact. 5, 3, 185-223.

Benford, S., Greenhalgh, C., Craven, M., Walker, G., Regan, T., and Morphett, J. 2000. Inhabited TV: Broadcasting interaction from within collaborative virtual environments. ACM Trans. Comput.-Hum. Interact. $7,4,510-547$.

Benford, S., Seager, W., Flintham, M., Anastasi, R., Rowland, D., Humble, J., Stanton, D., Bowers, J., Tandavanitj, N., Adams, M., Row Farr, J., Oldroyd, A., and Sutton, J. 2004. The error of our ways: The experience of self-reported position in a location-based game. In Proceedings of Ubicomp'04. 70-87. Nottingham, UK.

Benford, S., Crabtree, A., Reeves, S., Sheridan, J., Dix, A., Flintham, M., and Drozd, A. 2006. The frame of the game: Blurring the boundary between fiction and reality in mobile experiences. In Proceedings of the SIGCHI Conference on Human Factors in Computing Systems (CHI'06), ACM, New York, 427-436.

Benford, S., Giannachi, G., Koleva, B., and Rodden, T. 2009. From interaction to trajectories: Designing coherent journeys through user experiences. In Proceedings of the SIGCHI Conference on Human Factors in Computing Systems (CHI'09). ACM, New York.

Benford, S., Crabtree, A., Flintham, M., Greenhalgh, C., Koleva, B., Adams, M., Tandavanitj, N., Row Farr, J., Giannachi, G., and Lindt, I. 2011. Creating the spectacle: Designing interactional trajectories through spectator interfaces. ACM Trans. Comput.-Hum. Interact. 18, 3, Article 11.

Benford, S., Greenhalgh, C., Giannachi, G., Walker, B., Marshall, J., and Rodden, T. 2012. Uncomfortable interactions. In Proceedings of the SIGCHI Conference on Human Factors in Computing Systems (CHI'12). ACM, New York.

Bentley, R., Hughes J. A., Randall, D., Rodden, T., Sawyer, P., Sommerville, I., and Shapiro, D. 1992. Ethnographically-informed systems design for air traffic control. In Proceedings of CSCW'92. ACM, New York, 123-129.

Bowen, G. 2006. Grounded theory and sensitizing concepts. Int. J. Qualitat. Meth. 5, 3.

Buxton Collection. 2011. Website program for the Buxton Collection at CHI 2011. chi2011.org/program/buxton.html (last accessed 7/12).

Candy, L. and Edmonds, E. A. 2002. Explorations in Art and Technology. Springer-Verlag, Berlin.

Costello, B., Muller, L., Amitani, S., and Edmonds, E. 2005. Understanding the experience of interactive art: Iamascope in Beta_Space. In Proceedings of the 2nd Australasian Conference on Interactive Entertainment. (Sydney, Australia)

Crabtree, A. and Rouncefield, M. 2012. Doing Design Ethnography. Springer, Berlin.

Crabtree, A., Benford, S., Greenhalgh, C., Tennent, P., Chalmers, M., and Brown, B. 2006. Supporting ethnographic studies of ubiquitous computing in the wild. In Proceedings of the 6th Conference on Designing Interactive Systems (DIS'06). ACM, New York, 60-69.

Crabtree, A., Benford, S., Rodden, T., Greenhalgh, C., Flintham, M., Anastasi, R., Drozd, A., Adams, M., Row-Farr, J., Tandavanitj, N., and Steed, A. 2004. Orchestrating a mixed reality game 'on the ground'. In Proceedings of the SIGCHI Conference on Human Factors in Computing Systems (CHI'04). ACM, New York, 391-398.

Crabtree, A., Rodden, T., Tolmie, P., and Button, G. 2009. Ethnography considered harmful. In Proceedings of the 27th International Conference on Human Factors in Computing Systems (CHI'09). ACM, New York, 879-888.

CREATOR. 2012. Website for the CREATOR Digital Economy research cluster, www.creatorproject.org (last accessed 7/12).

DiSalvo, C., Boehner, K., Knouf, N., and Sengers, P. 2009. Nourishing the ground for sustainable HCI: Considerations from ecologically engaged art. In Proceedings of the 27th International Conference on Human Factors in Computing Systems (CHI'09). ACM, New York, 385-394.

Dixon, S. 2007. A History of New Media in Theater, Dance, Performance Art, and Installation. MIT Press.

EPSRC 2012. Report of the EPSRC review of human computer interaction research in the UK. http://www.epsrc.ac.uk/SiteCollectionDocuments/Publications/reports/HCIReview.pdf. 
Flintham, M., Anastasi, R., Hemmings, T., Crabtree, A., Greenhalgh, C., and Rodden, T. 2003. Where online meets on-the-streets: Experiences with mobile mixed reality games. In Proceedings of the SIGCHI Conference on Human Factors in Computing Systems. 5-10, 569-576.

Flintham, M., Smith, K., Benford, S., Capra, M., Green, J., Greenhalgh, C., Wright, M., Adams, M., Tandavanitj, N., Row Farr, J., and Lindt, I. 2007. Day of the figurines: A slow narrative-driven game for mobile phones using text messaging. In Proceedings of Pergames 2007.

Galani, A. and Chalmers, M. 2004. Seamful interweaving: Heterogeneity in the theory and design of interactive systems. In Proceedings of the 5th Conference on Designing Interactive Systems (DIS'04). ACM, New York, 243-252.

Garfinkel, H. 1967. Studies of the routine grounds of everyday activities. Studies in Ethnomethodology, Prentice-Hall, 35-75.

Gaver, W., Beaver, J., and Benford, S. 2003. Ambiguity as a resource for design. In Proceedings of the SIGCHI Conference on Human Factors in Computing Systems (CHI'03). ACM, New York, pp. 233-240.

Giannachi, G. and Benford S. 2008. Temporal expansion in blast theory's day of the figurines. PAJ: $A$ J. Performance and Art. 30, 3, MIT Press.

Giannachi, G., Rowland, D. Benford, S., Foster, J., Adams, M., and Chamberlain, A. 2010. Blast theory's rider spoke, its documentation and the making of its replay archive. Contemp. Theatre Rev. 3, 20, 353-367.

Glaser, B. G. and Strauss, A. 1967. Discovery of Grounded Theory. Aldine, London.

Graves Petersen, M., Hallnäs, L., and Jacob, R. 2008. Introduction to special issue on the aesthetics of interaction. ACM Trans. Comput.-Hum. Interact. 15, 3.

Greenhalgh, C., French, A., Tennent, P., Humble, J., and Crabtree, A. 2007. From replaytool to digital replay system. In Proceedings of the International Conference on e-Social Science.

Heath, C. and Luff, P. 1991. Collaborative activity and technological design: Task coordination in London underground control rooms. In Proceedings of the 2nd European Conference on Computer-Supported Cooperative Work. 65-80.

Koleva, B., Schnädelbach, H., Benford, S., and Greenhalgh, C. 2000. Traversable interfaces between real and virtual worlds. In Proceedings of Human Factors in Computing Systems (CHI'00). ACM, New York, $233-240$.

Koleva, B., Taylor, I., Benford, S., Fraser, M., Greenhalgh, C., Schnadelbach, H., vom Lehn, D., Heath, C., Row-Farr, J., and Adams, M. 2001. Orchestrating a mixed reality performance. In Proceedings of the SIGCHI Conference on Human Factors in Computing Systems (CHI'01). ACM, New York, 38-45.

Koppel, M., Bailly, G., Müller, J., and Walter, R. 2012. Chained displays: Configurations of public displays can be used to influence actor-, audience-, and passer-by behavior. In Proceedings of the ACM Annual Conference on Human Factors in Computing Systems (CHI'12). ACM, New York, 317-326.

Marshall, J., Rowland, D., Egglestone, S., Benford, S., Walker, B., and McAuley, D. 2011. Breath control of amusement rides. In Proceedings of the ACM Annual Conference on Human Factors in Computing Systems (CHI'11). ACM, New York.

Murphy, E. and Dingwall, R. 2001. The Ethics of Ethnography. In Handbook of Ethnography, P. Atkinson, et al. Eds., Sage. 339-351.

Oppermann, L., Broll, G., Capra, M., and Benford, S. 2006. Extending authoring tools for location-aware applications with an infrastructure visualization layer. In Proceedings of the 8th International Conference on Ubiquitous Computing (UbiComp'06). Springer-Verlag, Berlin, 52-68.

PLAN 2012. Website for the Pervasive and Locative Arts Network. www.open-plan.org (last accessed 7/12).

Reeves, S. 2011. Designing Interfaces in Public Settings. Springer.

Reeves, S., Benford, S., O’Malley, C., and Fraser, M. 2005. Designing the spectator interface. In Proceedings of the ACM Annual Conference on Human Factors in Computing Systems (CHI'05). ACM, New York, 741-750.

Rogers, Y. 2011. Interaction design gone wild: Striving for wild theory. Interactions 18, 4, 58-62.

Rogers, Y. 2012. HCI Theory: Classical, Modern and Contemporary. Morgan \& Claypool.

Schnädelbach, H., Egglestone, S. R., Reeves, S., Benford, S., Walker, B., and Wright, M. 2008. Performing thrill: Designing telemetry systems and spectator interfaces for amusement rides. In Proceedings of the ACM Annual Conference on Human Factors in Computing Systems (CHI'08). ACM, New York, 1167-1176.

Sengers, P. and Gaver, W. 2006. Staying open to interpretation: Engaging multiple meanings in design and evaluation. In Proceedings of DIS'06. ACM, New York, 99-108.

Sheridan, J. G. 2006. Digital live art: Mediating wittingness in playful arenas. Ph.D. thesis, Lancaster, UK, www.jennifersheridan.com/dla.html. 
Star, S. L. 1989. Institutional ecology, 'translations' and boundary objects: Amateurs and professionals in Berkeley's Museum of Vertebrate Zoology. Soc. Stud. Sci. 19, 3, 387-420.

Strauss, A. and Corbin, J. 1998. Basics of qualitative research: Techniques and procedures for developing grounded theory, 2nd Ed., Sage, London, UK.

Taylor, R., Schofield, G., Shearer, S., Wallace, J., Wright, P., Boulanger, P., and Olivier, P. 2011. Designing from within: Humanaquarium. In Proceedings of the Annual Conference on Human Factors in Computing Systems (CHI'11). ACM, New York, 1855-1864.

Tolmie, P., Crabtree, C., Rodden, T., and Benford, S. 2008. Are you watching this film or what?: Interruption and the juggling of cohorts. In Proceedings of the ACM Conference on Computer Supported Cooperative Work (CSCW'08). ACM, New York, 257-266.

Vom Lehn, D., Heath, C., and Knoblauch, H. 2001. Configuring exhibits. In Verbal Art Across Cultures, Gunter Narr Verlag, Tubingen, 281-297.

Wands, B. 2007. Art of the Digital Age. Thames \& Hudson.

ZKM 2012. Website for the Zentrum fur Kunst und Medientechnologie. www.zkm.de (last accessed 7/12).

Received July 2012; revised January 2013, March 2013; accepted April 2013 